Revista de la Escuela de Ciencias de la Educación, año 14, nRo. 13, vol. 1, enero a junio de 2018. Páginas 19-39. ISSN 1851-6297 (DESDE DICIEMBRE DE 2006 A DICIEMBRE DE 2017). ISSN 2362-3349 (EN LINEA). COORDENAÇAO PEDAGÓGICA e seus elementos fundamentais. Sonaly Carvalho de Miranda da Silva.

\title{
COORDENAÇAO PEDAGÓGICA E SEUS ELEMENTOS FUNDAMENTAIS
}

\author{
Por Sonaly Carvalho de Miranda da Silva* \\ sonalysi@hotmail.com \\ Secretaría de Estado de Educación, Brasil
}

Recibido: 20/10/2016 - Aceptado 17/05/2017

\section{Resumo}

O presente artigo baseia-se na investigação cujo tema é "A Coordenação Pedagógica como Espaço de Conquista e Formação", pertencente a Facultad de Humanidad y Artes Mención Ciencias de la Educación de la Universidad Nacional de Rosario. Trata de compreender quais são os elementos fundamentais presentes na coordenação pedagógica da escola que contribuem para que os sujeitos nela envolvidos possam adquirir saberes, numa perspectiva de aprimorar, alterar ou aprofundar o que se pretende alcançar, para melhor organização do trabalho pedagógico na escola e na sala de aula. Para isso, adotamos como pressupostos teórico-metodológicos a epistemologia qualitativa de González Rey e a Teoria Histórico-Cultural de Vygotsky. TrabaIhamos com duas escolas públicas de ensino fundamental, uma anos iniciais e outra anos finais.A apreciação das informações nos possibilitou chegar a quatro elementos: 1) O Sujeito Professor: emoções e pensamentos; 2) As Relações: o coletivo e a liderança pedagógica; 3) A Escola: estrutura administrativa e organização pedagógica; 4) A Formação: conhecimento e saberes. Assim, pretendemos contribuir com conhecimentos que possibilitem proporcionar uma visão de coordenação pedagógica, como ferramenta de enriquecimento educacional, de formação continuada do professor e de construção de um projeto Político-Pedagógico, todos necessários para a concretização de uma educação de qualidade social.

* É Doutora em Ciência da Educação pela Faculdade de Humanidade e Artes da Universidade Nacional de Rosario, e minha Tese se intitula: A Coordenação Pedagógica como Espaço de Conquista e Formação, 2015. Atualmente estou exercendo a função de professora formadora na Escola de Aperfeiçoamento dos Profissionais da Educação EAPE,da Secretaria de Estado de Educação do Distrito Federal - SEDF - Brasil. 
Revista de la Escuela de Ciencias de la Educación, año 14, nRo. 13, vol. 1, enero a junio de 2018. Páginas 19-39. ISSN 1851-6297 (DESDE DICIEMBRE DE 2006 A DICIEMBRE DE 2017). ISSN 2362-3349 (EN LINNEA). COORDENAÇAO PEDAGÓGICA e seus elementos fundamentais. Sonaly Carvalho de Miranda da Silva.

Palavras chave: Coordenação pedagógica - Gestão escolar democrática Ambiente coletivo - Liderança pedagógica - Formação de professor.

\begin{abstract}
The present article covers an investigation regarding following the theme: "The Pedagogical Coordination as a Conquest and Training Space", belonging to the Humanities and Educational Science College at the National University of Rosario. The study's objective is to comprehend which the core elements of the pedagogic coordination and which aspects contributes more to improve the individual knowledge by the ones involved, in a perspective of ripening, altering or deepen the goals, aiming a better pedagogical work environment inside and outside the classroom. For this purpose, the theoretical-methodological assumptions of the qualitative epistemology of González Rey and the historic-cultural theory of Vygotsky where chosen. The article's work took place inside two public elementary schools, covering the first and last years of teaching. The information analysis lead us to four viewpoints: 1) The Teacher as a Subject: emotions and thoughts; 2) Relations: the collective and the pedagogical leadership; 3) The School: administrative structure and pedagogical organization; 4) Formation: acquaintance and knowledge. Therefore, this project's intention is to contribute unfolding the pedagogical coordination as a tool of educational enlighten, especially regarding the teacher's continued training and the construction of a Political-Pedagogical Project, which are essential means to reach educational standards and social quality.
\end{abstract}

Keywords: Pedagogical coordination - Democratic school management Public school environment - Pedagogical leadership - Teacher's training.

\title{
1 - Introdução
}

Questões referentes à coordenação pedagógica têm se constituído em frequente alvo de atenção, principalmente nas políticas públicas educacionais do Distrito Federal. Quais as razões dessa preocupação tão nítida e tão persistente? Será mesmo importante que nós, profissionais da educação, acompanhemos toda essa discussão e nela nos envolvamos? Como estamos concebendo o espaço/tempo de coordenação pedagógica na escola?

Apesar da sua existência, notamos que esse espaço, conquistado por meio de lutas e greves dos professores, passou a ser criticado e desacreditado. A grande queixa é a utilização deste espaço para repasse de informes e práticas burocráticas, caracterizado por reduzidos momentos de formação, ausência de reflexão da práxis pedagógica, desfavorecendo o diálogo e as ações coletivas.

Incomodou-nos saber que poucos são os professores que conseguem melhorar suas práticas nesse espaço/tempo, e que são raras as escolas que 
Revista de la Escuela de Ciencias de la Educación, año 14, nRo. 13, vol. 1, enero a junio de 2018. Páginas 19-39. ISSN 1851-6297 (DESDE DICIEMBRE DE 2006 A DICIEMBRE DE 2017). ISSN 2362-3349 (EN LINEA). CoORDENAÇAO PEDAGÓGICA e seus elementos fundamentais. Sonaly Carvalho de Miranda da Silva.

conseguem organizar sua coordenação para a melhoria na qualidade do seu trabalho pedagógico.

Inicialmente, ao nos questionarmos sobre quais seriam as situações que ocasionavam o desenvolvimento desse quadro, a justificativa mais provável era o desinteresse do próprio professor, e em seguida, a falta de gestão. Porém, ao retratarmos a coordenação pedagógica na prática, deparamos com outros aspectos conflitantes nas escolas públicas da rede de ensino do Distrito Federal, como: falta de coordenadores; espaços inadequados; descontinuidade de momentos para estudo em decorrência de lacunas na organização do planejamento do trabalho escolar e a valorização da dimensão técnica em detrimento ao aprofundamento teórico-prático pedagógico.

Isso nos motivou a realizar a investigação para compreender quais elementos interferem e prevalecem na coordenação pedagógica da escola a ponto de gerar a sua efetiva realização e de promover o crescimento profissional do professor e de todo o ambiente educacional.

Outro ponto relevante foi que, no momento da realização do estudo, as escolas públicas do Distrito Federal vivenciavam o processo de reformulação do currículo. Este fatonecessitava de uma reflexão pedagógica democrática no espaço/tempo da coordenação pedagógica da escola de maneira coletiva.

Cabe destacar que o espaço/tempo da coordenação pedagógica na escola, é destinado a elaboração e acompanhamento do Projeto Político-Pedagógico e da reflexão da práxis na formação continuada do professor no espaço escolar, visando a melhoria da qualidade do ensino público para todos. Podese afirmar que é por intermédio da coordenação pedagógica que as "coisas" acontecem na escola. A coordenação pedagógica é, em outras palavras, o coração da escola, o espaço central em que a coletividade pode decidir e atuar.

Julgamos importante ressaltar que vivemos um momento histórico no qual os acontecimentos sociais, econômicos, tecnológicos e culturais estão marcados por rápidas transformações, exigindo-nos uma nova postura com relação ao outro, a nós mesmos e ao conhecimento. O tema fundamental para atender a toda essa complexidade é a formação. Nesse âmbito, os profissionais da educação necessitam reconstruir constantemente seus saberes, partindo da perspectiva crítico-reflexiva da prática pedagógica, buscando o seu desenvolvimento profissional.Questiona-se também, a capacidade da escola de adequar o que ela ensina, tendo como eixo central, o Projeto Político-Pedagógico da escola.

Nessas reflexões podemos e devemos recorrer aos documentos oficiais, como a Lei de Diretrizes e Bases da Educação brasileira nº 9.394 de 1996 (Lei $n^{\circ}$ 9.394, 1996), que contribuiu com significativas mudanças no âmbito administrativo das instituições educacionais.A Lei asseguraao professor profissional, no Artigo $n^{\circ}$ 67, o aperfeiçoamento continuado, inclusive com licenciamento periódico remunerado; piso salarial profissional; progressão funcional baseada na titulação ou habilitação e na avaliação do desempenho; um 
Revista de la Escuela de Ciencias de la Educación, año 14, nRo. 13, vol. 1, enero a junio de 2018. Páginas 19-39. ISSN 1851-6297 (DESDE DICIEMBRE DE 2006 A DICIEMBRE DE 2017). ISSN 2362-3349 (EN LINNEA). COORDENAÇAO PEDAGÓGICA e Seus elementos fundamentais. Sonaly Carvalho de Miranda da Silva.

período reservado a estudos, planejamento e avaliação incluídos na carga horária e condições adequadas de trabalho.

Recentemente foi implantada no Distrito Federal, a Lei de Gestão Escolar Democrática $n^{\circ} 4.751 / 2012$, que definiu as bases do Sistema de Ensino e aGestão Democrática do Ensino Público, tendo como finalidade "[...] garantir a centralidade da escola no sistema e seucaráter público quanto ao financiamento, à gestão e à destinação" (BRASÍLIA, 2012). Vale salientar que o termo gestão, quando relacionado à educação não é a simples substituição à palavra administração. A gestão assume a dimensão política e social, participativa, autônoma e interativa, influenciando todas as ações e aspectos da educação na sua totalidade (BRASIL, 1996).

Entendemos a relevância do espaço/tempo da coordenação pedagógica e da necessidade de se criar ideia e teoria sobre o tema, com a preocupação de contribuir com o aprimoramento dos professores e professoras que atuam na escola. Julgamos que uma educação de qualidade para todos, como a que defendemos, requer valorizar a coordenação pedagógica como espaço de reflexão e formação, para que o professor possa aprimorar a sua realidade pedagógica e assumir postura participativa e investigativa, dialogando com a própria ação.

Para isso, recorremos também aos estudos feitos por vários pesquisadores e estudiosos do campo. Segundo Veiga (2001), a escola necessita assumir a dimensão democrática na sua organização pedagógica a fim de superar os conflitos e romper com o trabalho fragmentado. Desse modo preserva-se a visão de totalidade e de autonomia ao delinear sua própria identidade por meio da construção coletiva do Projeto Político-Pedagógico da escola. Para isso é necessário um momento destinado ao debate, ao diálogo, à reflexão coletiva, de maneira que as ações planejadas reflitam no trabalho do professor e na dinâmica interna da sala de aula.

Desse ponto de vista, Vasconcellos (2008) enfatiza que o espaço da coordenação pedagógica propicia realizar atividades a partir dos problemas reais da escola. Surge a possibilidade de se criar objetivos comuns que farão da coordenação pedagógica o espaço de reflexão, favorecendo a formação de uma equipe de trabalho coesa e integrada, dentro do princípio da coletividade. A dimensão reflexiva na coletividade oportuniza o resgate do saber do professor. Dessa maneira, novas consciências são despertadas e motivadas a assumir tarefas num nível mais complexo e crítico.

Nóvoa (1992) destaca a importância das situações problemas relacionadas ao cotidiano pedagógico ou educativo,na formação do professor, e considera a escola o espaço privilegiado e concreto de articulação entre problema e formação, no processo de seu desenvolvimento profissional.

Segundo Schön (2000), o professor, ao definir os meios e os fins interativamente, decide o caminho mais relevante para solucionar a situação problema de maneira inovadora. 
Revista de la Escuela de Ciencias de la Educación, año 14, nRo. 13, vol. 1, enero a junio de 2018. Páginas 19-39. ISSN 1851-6297 (DESDE DICIEMBRE DE 2006 A DICIEMBRE DE 2017). ISSN 2362-3349 (EN LINEA). CoORDENAÇAO PEDAGÓGICA e seus elementos fundamentais. Sonaly Carvalho de Miranda da Silva.

Demo (2002) enfatiza a formação como uma reconstrução que se inicia de dentro para fora. Assim, não pode ser imposta, pois, segundo o autor, não se aprende na condição de objeto.

Para Santos (2002), a experiência adquirida ao longo da carreira, tanto profissional como pessoal, marca e caracteriza o trabalho e a trajetória docente, que busca relacionar a sua vivência educativa com os elementos novos, para solucionar problemas na execução do seu trabalho. Essa situação cria tipos de classificações, que o docente utiliza como normas e critérios nas suas ações, marcando sua trajetória profissional e a maneira como realiza o seu trabalho.

Raposo (2006) afirma que a formação acontece por meio da discussão, na construção de hipóteses, observando e revendo argumentos, apoiando-se nas teorias e pesquisas, numa construção dinâmica em que a teoria dialogue com a prática e a ação com a reflexão.

Para Tardif (2012), o saber do professor é o resultado de negociação entre diversos grupos dentro de um contexto social profissional, que ao longo da sua história é incorporado, modificado, adaptado, à medida em que aprende a ensinar ao fazer o seu trabalho.

Segundo Santos (2013), a interação está baseada na construção de ações coletivas de reflexão; de elaboração e execução; de avaliação e reavaliação, de organização e reorganização do trabalho pedagógico da escola. Para o autor, o movimento dialético é indispensável ao exercício da práxis. Dessa maneira, o espaço da coordenação pedagógica pode ser visto como primordial para a efetivação dessa interação. É no grupo que o sentimento de pertencimento se processa e é a dialogicidade que contribui para a formação da emoção do pertencimento.

Esses são temas fundamentais que embasaram o processo da investigação. A pesquisa nessa perspectiva, busca construir um novo olhar e uma atitude diferente frente à realidade.Para isso, apresentaremos os resultados oriundos do estudo e da busca da compreensão sobre os elementos fundamentais presentes na coordenação pedagógica da escola que contribuem para que os sujeitos nela envolvidos possam adquirir saberes, numa perspectiva de aprimorar, alterar ou aprofundar o que se pretende alcançar, para melhor organização do trabalho pedagógico na escola e na sala de aula.

\section{2 - Metodologia}

A base epistemológica da investigação é baseada na concepção de desenvolvimento e aprendizagem apresentada por Vygotsky. Em sua concepção, o ato educativo ocorre quando o sujeito interage e aprende com o outro mais capaz. Considera assim, a dimensão social, cultural histórica e as relações emocionais do sujeito no coletivo. No enfoque qualitativo proposto por Gonzáles Rey, a investigação se configura pelo caráter construtivo-interpretativo 
Revista de la Escuela de Ciencias de la Educación, año 14, nRo. 13, vol. 1, enero a junio de 2018. Páginas 19-39. ISSN 1851-6297 (DESDE DICIEMBRE DE 2006 A DICIEMBRE DE 2017). ISSN 2362-3349 (EN LINNEA). COORDENAÇAO PEDAGÓGICA e seus elementos fundamentais. Sonaly Carvalho de Miranda da Silva.

que leva em conta uma posição reflexiva, caracterizada por um modelo teórico, pelo pensamento do investigador, pelo diálogo e a comunicação, superando o princípio estímulo-resposta na busca de desenvolver outros modelos de compreensão na construção teórica, sempre considerando o sentido subjetivo dos sujeitos. Neste sentido, ambos os autores propõem uma abordagem interacionista, isto é, consideram o conhecimento como uma produção do ser humano, interpretativa, interativa e inserida em um contexto social.

Para a constituição da investigação focamos em duas escolas públicas da Secretaria de Estado de Educação do Distrito Federal - Brasil, uma de ensino fundamental anos iniciais denominada de Escola-1 e outra do mesmo nível, anos finais denominada de Escola-2. A ideia de selecionar duas escolas de modalidades de ensino diferentes, não teve o objetivo de comparar uma escola com a outra, senão, buscar pontos convergentes para a construção da informação.Para escolher as escolas optou-se naquelas que obtiveram o título de excelência no Índice de Desenvolvimento da Educação Básica - Ideb de 2012, período da investigação. O Ideb é o indicador para as políticas públicas em favor da qualidade no campo educacional. O índice é calculado com base no desempenho do estudante em avaliações do Sistema Nacional de Avaliação da Educação Básica (Saeb) e na Prova Brasil (Língua Portuguesa e Matemática), levando-se em conta, também, a taxa de reprovação e de evasão. O Índice é medido a cada dois anos e exibido numa escala que vai de zero a dez. A escola que obtém nota igual ou superior a seis é considerada uma escola de bom nível.

Ao selecionar as escolas surgiu uma curiosidade: Quais foram as ações desenvolvidas nessas escola que as fizeram destacar-se das demais em tão pouco tempo? (O primeiro resultado do Ideb foi publicado em 2007). O que faziam as mesmas, que as outras escolas não notaram, já que possuíam muitas características semelhantes? Para responder a estas perguntas adentramos no "coração da escola": a coordenação pedagógica.

A coordenação pedagógica da Escola-1 acontecia, obedecendo a determinação da SEDF, isto é, 15 (quinze) horas semanais, assim distribuídas: 12 (doze) horas semanais no ambiente escolar e três horas não necessariamente dentro da escola, no horário contrário ao da regência do professor (PPP da Escola-1, 2010).

De acordo com o PPP da Escola-1 (2010), a organização dessas 12 (doze) horas ficou assim distribuída: um encontro coletivo semanal de cada série com o coordenador pedagógico e com a direção, para o planejamento geral; três dias de coordenação para preparação de material, estudo e elaboração de relatórios; e um dia de coordenação individual.

A Escola-1 funcionava em dois turnos e atendia estudantes de seis a 10 (dez) anos, distribuídos em 30 (trinta) turmas, sendo 15 (quinze) no turno matutino e 15 (quinze) no turno vespertino, totalizando, aproximadamente, 800 (oitocentos) estudantes. 
Revista de la Escuela de Ciencias de la Educación, año 14, nRo. 13, vol. 1, enero a junio de 2018. Páginas 19-39. ISSN 1851-6297 (DESDE DICIEMBRE DE 2006 A DICIEMBRE DE 2017). ISSN 2362-3349 (EN LiNEA). CoORDENAÇAO PEDAGÓGICA e seus elementos fundamentais. Sonaly Carvalho de Miranda da Silva.

O Projeto Político-Pedagógico da escola, em linhas gerais, era articulado no processo da leitura e da escrita, utilizando a avaliação formativa, a auto avaliação, como norteadora do redirecionamento das ações para superar as dificuldades encontradas pelos estudantes. A Escola-1 trabalhava com projetose oferecia reforço escolar e atendimento aos estudantes com deficiência e/ ou com dificuldades de aprendizagem, no contra turno.

A Escola-2 atendia estudantes do $6^{\circ}$ ao $9^{\circ}$ ano, na faixa etária de 10 a 16 anos de idade, distribuídos em 34 (trinta e quatro) turmas, sendo 17 (dezessete) de $7^{\mathrm{a}}$ série $/ 8^{\circ}$ anos e $8^{\mathrm{a}}$ série $/ 9^{\circ}$ anos, no turno matutino e 17 (dezessete) de $5^{\mathrm{a}}$ série $/ 6^{\circ}$ anos e $6^{\mathrm{a}}$ série $/ 7^{\circ}$ anos, no turno vespertino, totalizando 1.128 (mil cento e vinte oito) estudantes.

O PPP da Escola-2 estava pautado nos princípios da alegria, da simplicidade e da fraternidade, transformando informação em conhecimento, na construção do cidadão valorizado nos seus talentos e comprometido com situações do contexto social. (PPP da Escola-2, 2012). A escola organização da escola era em salas-ambientes,onde os estudantes se deslocavam de acordo com o horário semanal da turma. Eram 24 (vinte e quatro) salas, nas quais foram distribuídas as disciplinas. O horário foi organizado em aulas duplas, para maior aproveitamento curricular e também para diminuir o número de trocas e de circulação dos estudantes.

A Escola-2 também trabalhava com projetos e realizava avaliações interdisciplinares bimestrais que englobavam todas as disciplinas. Para tanto, organizavam planos de trabalhos em conjunto, com o objetivo de integrar os aspectos comuns dos componentes curriculares, articulando, assim, os assuntos estudados (PPP da Escola-2, 2012).

O PPP da Escola-2, ao retratar a coordenação pedagógica, obedeceu à determinação da SEDF, que define o quantitativo de 12 (doze) horas semanais de coordenação no ambiente escolar e três horas não necessariamente dentro da escola. A realização da coordenação pedagógica acontecia no horário contrário ao da regência do professor. A distribuição da coordenação pedagógica na Escola-2 foi assim definida: segunda-feira - coordenação coletiva da área e/ou individual e/ou formação continuada dos professores de Geografia e História; terça-feira - coordenação coletiva da área e/ou individual e/ou formação continuada dos professores de Ciências e Matemática; quarta-feira - coordenação coletiva envolvendo todas as áreas de conhecimento; quinta-feira - coordenação coletiva da área e/ou individual e/ou formação continuada dos professores de Códigos e Linguagens (Língua Portuguesa, Artes, Educação Física e Inglês); sexta-feira - coordenação individual, não necessariamente no ambiente da escola (PPP da Escola-2, 2012).

O momento empírico da produção teórica foi realizado por meio dos seguintes instrumentos indutores de informação (González Rey, 1999): a observação, a análise documental e a entrevista semiestruturada. Os ins- 
Revista de la Escuela de Ciencias de la Educación, año 14, nRo. 13, vol. 1, enero a junio de 2018. Páginas 19-39. ISSN 1851-6297 (DESDE DICIEMBRE DE 2006 A DICIEMBRE DE 2017). ISSN 2362-3349 (EN LINNEA). COORDENAÇAO PEDAGÓGICA e Seus elementos fundamentais. Sonaly Carvalho de Miranda da Silva.

trumentos, segundo González Rey (2003), "são definidos como sendo toda situação ou recurso onde se permite que o outro se expresse de forma interativa no contexto da pesquisa sem ter a função de gerador de resultados, somente representa uma fonte de informação" (p. 42).

Sendo assim, foram selecionados 20 (vinte) sujeitos individuais, representando $15 \%$ do total de professores de cada uma das escolas. Na pesquisa, buscamos uma metodologia de conversação (grifo nosso), para que houvesse a maior integração dos participantes a fim de atingir o maior grau de expressão subjetiva.

Para González Rey (2005)é dessa maneira,que se caracteriza a produção intelectual do pesquisador "inseparável do processo de sentido subjetivo marcado por sua história, crenças, representações, valores, enfim, de todos os aspectos em que se expressa sua constituição subjetiva" (p. 36).

A observação foi a primeira opção para entrar no campo de atuação dos professores eobservar o grupo em suas manifestações e atuações na coordenação pedagógica. Construímos, assim, um roteiro de perguntas orientadoras para a observação, relacionadas às palavras chave da pesquisa:Como é a liderança no espaço da coordenação pedagógica? Como a gestão interfere na coordenação pedagógica? Como são realizadas as interações na coordenação pedagógica? Como se organiza a coordenação pedagógica? Quem planeja a coordenação pedagógica? Como é o planejamento da coordenação pedagógica? O que é considerado nesse planejamento? Como é a execução do planejamento da coordenação pedagógica? A coordenação está sendo espaço de formação continuada? Como é realizada a construção dos conhecimentos? A formação é informal ou formal? A formação é intencional? Existe a construção coletiva? Qual é a postura do coordenador?

Cabe destacar que as observações ocorreram três vez por semana nas coordenações do turno matutino e vespertino das escolas, com duração em torno de 2 (duas) horas cada, de maneira não participativa e sujeitas a todo tipo de variáveis e variantes, durante um semestre.As observações foram escritas em diário de campo para facilitar o processo de revisão das ideias produzidas ao longo do processo da pesquisa. Lakatos e Marconi (2003) chamam a atenção para a limitação da observação individual com relação ao controle das ocorrências, mas citam como ponto positivo a objetividade das informações.

Como estratégia complementar, buscamos analisar os documentos que norteavam as ações pedagógicasexistentes nas instituições. Os documentos analisados foram: Currículo em Movimento da Educação Básica - SEDF Pressupostos teóricos; Projeto Político-Pedagógico Prof. Carlos Mota SEDF - Estrutura organizacional da SEDF; concepção, missão e objetivos institucionais; formação dos profissionais da educação e gestão administrativa e pedagógica; Projeto Político-Pedagógico da Escola-1,Projeto Político-Pedagógico da Escola-2 - Objetivos e propostas; organização; planejamento. 
Revista de la Escuela de Ciencias de la Educación, año 14, nRo. 13, vol. 1, enero a junio de 2018. Páginas 19-39. ISSN 1851-6297 (DESDE DICIEMBRE DE 2006 A DICIEMBRE DE 2017). ISSN 2362-3349 (EN LiNEA). CoORDENAÇAO PEDAGÓGICA e seus elementos fundamentais. Sonaly Carvalho de Miranda da Silva.

Creswell (2010), destaca que a análise documental possui limitações. Uma delas é que corremos o risco de os documentos estaremincompletos, imprecisos ou não serem autênticos.

Assim, utilizamos mais outra estratégia de produção de informação: a entrevista semiestruturada. $O$ roteiro foi assim estruturado:

No primeiro bloco - apresentação do entrevistado: onde se formou, quanto tempo de magistério, quanto tempo na escola, suas experiências no magistério e formação profissional.

No segundo bloco - apresentação das questões teóricas: O que é uma coordenação pedagógica? Qual é o objetivo da coordenação pedagógica na escola? Quem deveria participar (direta ou indiretamente) da coordenação pedagógica e qual o papel de cada uma dessas pessoas? O que é formação continuada do professor? Como deveria acontecer a formação continuada do professor na escola? Quem seriam os responsáveis por essa formação?

No terceiro bloco - organização do trabalho pedagógico: Como se organiza a coordenação pedagógica no contexto da escola? Quem são os participantes do processo de planejamento, execução e avaliação da coordenação pedagógica e quais são os níveis de atuação de cada um deles? Como se organiza a formação continuada do professor no contexto da escola? Quem são os participantes do processo de planejamento, execução e avaliação da formação continuada do professor na escola e quais são os níveis de atuação de cada um deles? Quais elementos contribuem para tornar a coordenação pedagógica espaço de construção coletiva e de formação continuada do professor?

As entrevistas foram realizadas no ambiente escolar, acontecendo no contra turno do professor. Foram entrevistados: o Vice-diretor; o Supervisor Pedagógico, o coordenador pedagógico e os professores. As entrevistas foram gravadas e realizadas com um respondente de cada vez. Neste processo procuramos interferir o mínimo possível, dando liberdade para que o entrevistado organizasse o seu discurso e associações em relação ao tema proposto. González Rey (1999) esclarece que a construção e a interpretação fazem parte de todo o procedimento de investigação qualitativa, inspirando novos pensamentos. Por isso é um processo abertoe não se apoia em coleta de dados, como nas investigações tradicionais.

Nesta perspectiva, utilizamos três momentos como estratégia de análise: leitura e transcrição de todo o material construído, definição de indicadores e categorias e o diálogo com o referencial teórico. À medida que líamos o material, distinguimos cada assunto por cores para representar os elementos percebidos pelos entrevistados e interpretados pelo entrevistador em cada instrumento empregado, de acordo com o objetivo da pesquisa: $\mathrm{O}$ amarelo se referia ao professor; o rosa, às relações; o azul, à escola e o verde, ao conhecimento. Esse processo de geração de dados, foi uma adaptação da 
Revista de la Escuela de Ciencias de la Educación, año 14, nRo. 13, vol. 1, enero a junio de 2018. Páginas 19-39. ISSN 1851-6297 (DESDE DICIEMBRE DE 2006 A DICIEMBRE DE 2017). ISSN 2362-3349 (EN LINNEA). COORDENAÇAO PEDAGÓGICA e seus elementos fundamentais. Sonaly Carvalho de Miranda da Silva.

estratégia de coleta de dados apresentada por Weber (2011), na realização de pesquisa sobre desenvolvimento familiar.

Primeiramente construímos quadros com três colunas para identificar os sujeitos envolvidos; o objeto e o conteúdo obtido por meio dos instrumentos; e as palavras selecionadas e interpretadas pela pesquisadora relacionadas ao objetivo da investigação. Nesse momento, destacamos com cores as palavras e ao mesmo tempo marcamos a (s) frase (s) de onde elas foram retiradas. Destacamos, que a análise de todos os materiais seguiram o mesmo padrão.

Quadro 1: Fragmento do quadro da entrevista

\begin{tabular}{|c|c|c|}
\hline Sujeitos & Entrevista & Elementos \\
\hline Entrevistadora & $\begin{array}{l}\text { E, na sua opinião, quais seriam os } \\
\text { elementos que contribuem para } \\
\text { tornar a coordenação pedagógica } \\
\text { espaço de formação continuada } \\
\text { na escola? }\end{array}$ & \\
\hline Professora-1 & $\begin{array}{l}\text { Eu acho que a escola já faz um tra- } \\
\text { balho bacana, interessante. A es- } \\
\text { cola sempre organiza atividades,- } \\
\text { momentos de reflexão, de estudo } \\
\text { mesmo. Trabalha questões que } \\
\text { são importantes né. Conscientiza } \\
\text { os professores, olha, por exemplo, } \\
\text { a questão de novas metodologias, } \\
\text { metodologias para trabalhar cer- } \\
\text { tos conteúdos, o que se espera } \\
\text { da escola hoje em dia. Então sem- } \\
\text { pre estar trazendo questões como } \\
\text { essa para que a gente reflita e } \\
\text { modifique nossa prática, melhore } \\
\text { nossa prática.Eu acho que a esco- } \\
\text { la faz um trabalho interessante. }\end{array}$ & $\begin{array}{l}\text { Organização } \\
\text { Reflexão } \\
\text { Estudo } \\
\text { Questões } \\
\text { pertinentes } \\
\text { Conscientização } \\
\text { dos professores } \\
\text { Reflexão } \\
\text { Mudança da prática } \\
\text { Satisfação }\end{array}$ \\
\hline
\end{tabular}

Fonte: dados da pesquisa

Em seguida, construímos outros quadros separando cada uma das cores elencadas. Nesse segundo quadro colocamos, em cada coluna, os nomes dos entrevistados/assunto, e todas as palavras citadas por eles na entrevista, interpretadas nas observações e presentes nos documentos analisados, re- 
Revista de la Escuela de Ciencias de la Educación, año 14, nRo. 13, vol. 1, enero a junio de 2018. Páginas 19-39. ISSN 1851-6297 (DESDE DICIEMBRE DE 2006 A DICIEMBRE DE 2017). ISSN 2362-3349 (EN LINEA). CoORDENAÇAO PEDAGÓGICA e seus elementos fundamentais. Sonaly Carvalho de Miranda da Silva.

ferentes àquela cor. A finalidade deste momento era conseguir visualizar, de maneira geral, a verbalização dos entrevistados e todas as palavras relacionadas àquele assunto.

Neste procedimento, observamos a presença de várias palavras repetidas e semelhantes entre si e que foram muito mencionadas por todos os entrevistados. Para interpretar de maneira mais objetiva, foram contadas cada uma dessas palavras em cada cor. Algumas palavras foram repetidas em cores diferentes, uma vez que em determinadas situações, se relacionavam melhor a um assunto ou outro. Um exemplo disso foi a palavra participação. Em algumas falas referia-se ao indivíduo e, em outras, ao grupo.

Após este recurso quantitativo, agrupamos as palavras com sentidos semeIhantes, relacionadas entre si, e, como consequência, formamos quatro grupos, que foram sintetizados no quadro identificação dos indicadores por cores.

\section{Quadro 2: Identificação dos indicadores por cores}

\begin{tabular}{|l|c|}
\hline \multicolumn{1}{|c|}{ Palavras Relacionadas entre Si } & Indicadores \\
\hline $\begin{array}{l}\text { Momento formativo; conhecimento; estudo; aprendiza- } \\
\text { gem mútua; formação; apropriação; êxito; criatividade; } \\
\text { atualização. }\end{array}$ & Aprendizagem \\
\hline $\begin{array}{l}\text { Troca de experiência; troca de ideias; liderança peda- } \\
\text { gógica; prática; troca de saberes; vivência; apoio; ex- } \\
\text { pressão; sugestão; compartilhar; discussão; conversa; } \\
\text { novidade. }\end{array}$ & $\begin{array}{c}\text { Troca de } \\
\text { informação }\end{array}$ \\
\hline $\begin{array}{l}\text { Informação; diversidade; explicação; acrescentar; me- } \\
\text { todologia; elaboração; pensamento criativo; contextua- } \\
\text { lização; explorar. }\end{array}$ & Pesquisa \\
\hline $\begin{array}{l}\text { Dificuldade; dia-a-dia; atividade significativa; lembrança; } \\
\text { critério; questionamento; mudança; esclarecimento; ava- } \\
\text { liação. }\end{array}$ & Reflexão \\
\hline
\end{tabular}

Fonte: dados da pesquisa

A partir deste ponto, organizamos por cores, o quadro complementar onde agrupamos os indicadores e definimos cada uma das categorias de análise: Amarelo - O Sujeito Professor: emoções e pensamentos; Rosa - As Relações: o coletivo e a liderança pedagógica; Azul - A Escola: estrutura administrativa e organização pedagógica; Verde - A Formação: conhecimento e saber. 
Revista de la Escuela de Ciencias de la Educación, año 14, nRo. 13, vol. 1, enero a junio de 2018. Páginas 19-39. ISSN 1851-6297 (DESDE DICIEMBRE DE 2006 A DICIEMBRE DE 2017). ISSN 2362-3349 (EN LINNEA). COORDENAÇAO PEDAGÓGICA e Seus elementos fundamentais. Sonaly Carvalho de Miranda da Silva.

\section{Quadro 3: Indicadores e Categorias}

\begin{tabular}{|l|c|}
\hline \multicolumn{1}{|c|}{ Indicadores } & Categorias \\
\hline $\begin{array}{l}\text { Compromisso; satisfação; Interesse; competência; } \\
\text { gostar; descontração; motivação; abertura; mu- } \\
\text { dança; postura do professor; dificuldade; saúde do } \\
\text { professor; valorização, reconhecimento; limitação } \\
\text { do professor; mudança; profissionalismo. }\end{array}$ & $\begin{array}{c}\text { O Sujeito Professor: } \\
\text { emoções e pensa- } \\
\text { mentos }\end{array}$ \\
\hline $\begin{array}{l}\text { Participação; grupo; coletivo; envolvimento; rela- } \\
\text { ções; coletividade; discussão; liderança pedagógi- } \\
\text { ca; diálogo; interação; trabalho conjunto; trabalho } \\
\text { em equipe; discussão; família. }\end{array}$ & $\begin{array}{c}\text { As Relações: o co- } \\
\text { letivo e liderança } \\
\text { pedagógica }\end{array}$ \\
\hline $\begin{array}{l}\text { Organização; planejamento; acompanhamento; } \\
\text { projeto; avaliação; objetividade; gestão democrá- } \\
\text { tica; estrutura; controle. }\end{array}$ & $\begin{array}{c}\text { A Escola: estrutura } \\
\text { administrativa e } \\
\text { organização peda- } \\
\text { gógica }\end{array}$ \\
\hline $\begin{array}{l}\text { Conhecimento; aprendizado; pesquisa; prática; } \\
\text { formação; reflexão; troca de informação; curso; es- } \\
\text { tudo; troca de saberes; formação continuada; troca } \\
\text { de ideia; conhecimento. }\end{array}$ & $\begin{array}{c}\text { A Formação: conhe- } \\
\text { cimento e saber }\end{array}$ \\
\hline
\end{tabular}

Fonte: dados da pesquisa

É importante ressaltar que as categorias apresentam características comportamentais e relacionais e, embora tenham suas especificidades, também possuem interdependência. Nessa perspectiva, a interdependência das categorias acontece ao retratamos o sujeito enredado em um determinado espaço de interações, cujas ações estão constantemente interferindo no ambiente e vice-versa. Essa relação simbiótica é que faz com que as categorias sejam percebidas umas nas outras.

A estratégia de construção e os procedimentos de organização dessas informações facilitaram a produção de ideias e, posteriormente, o terceiro momento: diálogo com o referencial teórico apresentado, o que nos conduziu ao alcance dos objetivos deste estudo.

\section{3 - Discussão dos resultados}

\section{1 - O Sujeito Professor: emoções e pensamentos}

Quando pretendemos compreender quais os elementos fundamentais necessários para fazer da coordenação pedagógica um espaço de conquista e 
Revista de la Escuela de Ciencias de la Educación, año 14, nRo. 13, vol. 1, enero a junio de 2018. Páginas 19-39. ISSN 1851-6297 (DESDE DICIEMBRE DE 2006 A DICIEMBRE DE 2017). ISSN 2362-3349 (EN LINEA). CoORDENAÇAO PEDAGÓGICA e seus elementos fundamentais. Sonaly Carvalho de Miranda da Silva.

de formação, não poderíamos desconsiderar o professor como sujeito subjetivo e histórico no seu processo de constituição. Segundo Pino (1996), "o indivíduo é uma versão singular e personalizada da realidade cultural em que está inserido" (p. 23). Desse modo, a construção das configurações subjetivas do Sujeito Professor dão sentido a suas ações.

Igualmente, Compreendemos o papel ativo do Sujeito Professor de modo circular e ascendente, isto é, os acontecimentos ocorridos no seu contexto sociocultural retornam para ele com diferentes impressões emocionais, que o modifica por meio da aprendizagem.

Essa relação de desenvolvimento bi-direcional do Sujeito Professor necessita de espaço de mediação. A mediação acontece a partir do momento em que se desdobram ações questionadoras, provocativas, originando desequilíbrio e ao mesmo tempo motivando e disponibilizando subsídios para o crescimento individual do Sujeito Professor e do grupo (Vasconcellos, 2008).

Para Cunha (2005), nas relações interpessoais, os signos e as operações de significação constituem-se como produto e processo de mediação entre sujeitos e pensamento singular dos indivíduos. Percebemos, assim, a relação dialética de si mesmo, com a participação do outro, na constituição do Sujeito Professor.

Entendemos que para o desenvolvimento do Sujeito Professor, ele precisa expor sua emoção e pensamento, e para isso, necessita de alguém que o ouça e também opine sobre o que ele pensa. Segundo González Rey (2005), "as emoções relacionam-se com as palavras em um espaço de sentido, não em uma relação abstrata e fora de contexto de ação do sujeito" (p. 38). Dessa maneira, a coordenação pedagógica necessita concretizar momentos que evocam expressões simbólicas, emanadas da emoção, na produção de sentidos subjetivos do Sujeito Professor tornando espaço de ação interpretativa do outro.

A coordenação pedagógica, nesse sentido, torna-se o espaço social e cultural criador de tensões, que oportuniza experiências concretas dentro do sistema de relações que ali ocorrem. É no espaço de coordenação pedagógica que podemos propiciar ao Sujeito Professor expressar seus interesses e habilidades, suas criações e opiniões, construídas ao longo de sua historicidade.

Por isso, é fundamental que o espaço de coordenação pedagógica seja um ambiente democrático, onde haja práticas curriculares variadas e participativas, propiciando condições para que o Sujeito Professor possa ser capaz de agir intencionalmente e voluntariamente para atingir determinados fins.

\section{2 - As Relações: o Coletivo e a Liderança Pedagógica}

Por certo, as relações sociais acontecem na interação comunicativa realizada em espaços que propiciam às pessoas se sentirem envolvidas e participantes (Cunha, 2005). 
Revista de la Escuela de Ciencias de la Educación, año 14, nRo. 13, vol. 1, enero a junio de 2018. Páginas 19-39. ISSN 1851-6297 (DESDE DICIEMBRE DE 2006 A DICIEMBRE DE 2017). ISSN 2362-3349 (EN LINNEA). COORDENAÇAO PEDAGÓGICA e Seus elementos fundamentais. Sonaly Carvalho de Miranda da Silva.

Nesse aspecto, Pino (1993) comenta que as relações sociais em que o sujeito está envolvido intervém no seu modo de se relacionar e no seu modo de ser. Portanto, é preciso constituir o espaço de convivência democrática, em que todos os envolvidos no processo educativo possam expressar opiniões.

A coordenação pedagógica, surge comoambiente destinado às discussões coletivas, avaliação e reflexão da realidade, na perspectiva da relação participativa de maneira efetiva.Esse princípio ficou evidenciado no discurso do entrevistado e representou a oportunidade de expressão e de relação entre todos:

\begin{tabular}{|l|l|}
\hline Vice-diretor-1 & $\begin{array}{l}\text { Há uma igualdade entre todos. E o que permeia todo o tra- } \\
\text { balho é o diálogo, é a participação de todos, é a opinião de } \\
\text { todos da escola, seja de um servidor, por exemplo, da área da } \\
\text { cantina, da área da limpeza, professor e até mesmo nós, que } \\
\text { estamos como gestores. Nada é imposto, tudo é construído } \\
\text { democraticamente. }\end{array}$ \\
\hline
\end{tabular}

Nessas relações, somos motivados a assumir posturas, compartilhar saberes e nos colocar abertos para as mudanças em prol da melhoria do trabaIho pedagógico. É a dialogicidade queinvoca a crença de conseguir lidar com obstáculos, e de se descobrir como professor profissional. Nesse processo, é provável que um contagie o outro, gerando novos sentidos que os modificam na sua maneira de ser e de agir no espaço social onde atuam. (Santos, 2013)

Para que a interação entre os professores aconteça de maneira intencional é preciso uma pessoa na escola, para assumir o papel de líder pedagógico. A ideia de Liderança Pedagógica ficou evidenciada na fala do entrevistado:

\begin{tabular}{|l|l|}
\hline Coorde- & $\begin{array}{l}\text { A Supervisora-2 põe a gente para pensar, pensar junto. ... a coi- } \\
\text { sa mais importante é vencer essa barreira que algumas pessoas } \\
\text { têm. Então, para isso a gente precisa ter um supervisor pedagó- } \\
\text { gico consciente do seu papel, como a gente tem a Supervisora-2. } \\
\text { nadora-4 } 4 \\
\text { Ela gosta do que ela faz, ela se planeja para isso, ela envolve as } \\
\text { to: você viu fulano? Estava meio distante; o que a gente vai fazer } \\
\text { para motivar? A gente está o tempo todo observando: se eu falo, } \\
\text { ela observa, se ela fala, eu observo. A gente está sempre de olho } \\
\text { na equipe para ver se está funcionando, que, na verdade é o que } \\
\text { a gente tem que fazer em sala também, né? Estar de olho para ver } \\
\text { quem que está desmotivado. Eu acho que é isso. }\end{array}$ \\
\hline
\end{tabular}

A Liderança Pedagógica atua em um sistema pluridimensional, integrando e articulando o individual e o social, carregado de valor simbólico e afetivo. Seu maior desafio está em instituir, consciente e intencionalmente, padrões de 
Revista de la Escuela de Ciencias de la Educación, año 14, nRo. 13, vol. 1, enero a junio de 2018. Páginas 19-39. ISSN 1851-6297 (DESDE DICIEMBRE DE 2006 A DICIEMBRE DE 2017). ISSN 2362-3349 (EN LINEA). CoORDENAÇAO PEDAGÓGICA e seus elementos fundamentais. Sonaly Carvalho de Miranda da Silva.

interação, visando a contribuir para a formação do sujeito proativo e autopoiético. Na perspectiva de Maturana (1997), autopoiése é a capacidade que o ser vivo tem de relacionar-se, agir e reagir diante das circunstâncias do meio, e se organizar a partir do conhecimento que adquire no próprio ato de viver, se auto sustentando.

A Liderança Pedagógica no espaço de coordenação pedagógica é primordial para que as ações e metas aconteçam de maneira integrada, compromissada e participativa, na construção de soluções para o desenvolvimento de competências coletivas.

Dessa maneira a dimensão da Liderança Pedagógica, na coordenação pedagógica, pretende organizar e dinamizar as ações com a finalidade de remeter cada Sujeito Professor a trabalhar em prol de um objetivo comum compartilhado, agregado ao sentimento de compromisso, de pertencimento e também de identidade do grupo.

\section{3 - A Escola: Estrutura Administrativa e Organização Pedagógica}

Segundo Moran (2007), a organização no ambiente escolar busca gerenciar todos os aspectos que norteiam as ações pedagógicas, levando-se em conta o diálogo e a coletividadepara se alcançar as metas estipuladas de forma coletiva. Nas escolas pesquisadas, percebemos que todos os serviços administrativos prestados existiam para servir ao pedagógico da escola.

\begin{tabular}{|l|l|}
\hline Professora-5 & $\begin{array}{l}\text { Na escola, há o compromisso de todos os seguimentos, } \\
\text { seja professores, seja direção, mecanografia, secretaria, } \\
\text { coordenação pedagógica, supervisão, coordenação dis- } \\
\text { ciplinar. Dentro desta escola, especificamente, todos os } \\
\text { segmentos acabam se envolvendo, tendo uma função } \\
\text { relevante, pois a escola é extremamente dinâmica, envol- } \\
\text { ve desde o pessoal da limpeza, que é preciso propiciar } \\
\text { aos meninos um ambiente saudável, para que eles não } \\
\text { tenham riscos de algum acidente, quanto coordenação } \\
\text { disciplinar, quanto supervisão, que fazem todo o trabalho } \\
\text { de apoio, junto com os professores, no desenvolvimento } \\
\text { das atividades. }\end{array}$ \\
\hline
\end{tabular}

A organização promove as condições para que o professor tenha mais autonomia nos assuntos da escola e as ações sejam mais transparentes. Foi considerado também, o espaço de coordenação pedagógica na escola: 
Revista de la Escuela de Ciencias de la Educación, año 14, nRo. 13, vol. 1, enero a junio de 2018. Páginas 19-39. ISSN 1851-6297 (DESDE DICIEMBRE DE 2006 A DICIEMBRE DE 2017). ISSN 2362-3349 (EN LINNEA). COORDENAÇAO PEDAGÓGICA e seus elementos fundamentais. Sonaly Carvalho de Miranda da Silva.

\begin{tabular}{|l|l|}
\hline \multirow{3}{*}{ Professora-5 } & $\begin{array}{l}\text { É o que funciona, é o coração da escola, porque a coorde- } \\
\text { nação pedagógica, ela envolve o que você quer exatamente } \\
\text { desenvolver em sala de aula com seus alunos. E também, } \\
\text { desenvolver os conteúdos de uma forma harmônica, inter- } \\
\text { disciplinar, já que na coordenação pedagógica você tem a } \\
\text { possibilidade de estar com outros colegas da sua área ou de } \\
\text { áreas diferentes e é um facilitador grande, eu acho, para as } \\
\text { atividades acontecerem de forma satisfatória. }\end{array}$ \\
\hline
\end{tabular}

Houve a constatação de uma organização educativa voltada para projetos.

\begin{tabular}{|l|l|}
\hline Professora-7 & $\begin{array}{l}\text { A escola tem que ter uma organização, e ela tem que dar } \\
\text { um norte para o professor. Eu acho que começa por aí. } \\
\text { Nesse norte, estão incluídos os projetos que a escola des- } \\
\text { envolve. A escola tem muitos projetos, eu acho bacana } \\
\text { isso, eu acho interessante. Eu nunca trabalhei em uma } \\
\text { escola que tivesse tantos projetos quanto esta, que fun- } \\
\text { cionam e não foram feitos assim de qualquer jeito. Quando } \\
\text { o projeto envolve o aluno, e ele quer fazer, porque de algu- } \\
\text { ma maneira ele vai se satisfazer, a coisa flui, impressionan- } \\
\text { te! Aqui, o projeto tem como base um tema central e você } \\
\text { tem que encontrar textos relacionados a esse tema central } \\
\text { que contemplem o seu conteúdo. }\end{array}$ \\
\hline
\end{tabular}

Assim, a escola materializa e projeta as suas intenções coletivas ao criar o seu Projeto Político-Pedagógico. Segundo o Currículo em Movimento da Educação Básica do Distrito Federal (2014), o Projeto Político-Pedagógico da Escola institui o pensamento coletivo da escola, levando-se em conta a sua realidade, que reflete, assim, na sua identidade, isto é, a maneira como a sua comunidade pensa, almeja e planeja a educação paraque seja integral, pública, democrática e de qualidade social.

O modo diferenciado de planejamento escolar as suas ações de ensino -aprendizagem desencadeia construções desafiadoras e provocadoras, tanto para os estudantes como para os professores. O desafio surge na perspectiva de oportunizar aos professores se reunirem no espaço da coordenação pedagógica, para refletir, planejar e avaliar de maneira coletiva, as estratégias didático-pedagógicas para que os estudantes possam aprender "permeados por incentivos constantes ao raciocínio, à problematização, ao questionamento e à dúvida" (Currículo em Movimento, 2014, p. 67). 
Revista de la Escuela de Ciencias de la Educación, año 14, nRo. 13, vol. 1, enero a junio de 2018. Páginas 19-39. ISSN 1851-6297 (DESDE DICIEMBRE DE 2006 A DICIEMBRE DE 2017). ISSN 2362-3349 (EN LINEA). CoORDENAÇAO PEDAGÓGICA e seus elementos fundamentais. Sonaly Carvalho de Miranda da Silva.

\section{4 - A Formação: Conhecimento e Saber}

A Categoria Formação surge quando nos perguntamos sobre a maneira como é realizada a construção do conhecimento e do saber do Sujeito Professor, principalmente no ambiente escolar, onde estão reunidos docentes, que trazem, cada um, a marca dos valores e da cultura que vivenciaram ao longo de sua história de vida e também profissional. A escola passa a ser palco das mudanças relacionadas ao saber do professor e é na coordenação pedagógica que os sujeitos envolvidos na ação formativa vão buscar um novo fazer que dê conta da complexidade do processo do conhecimento, para transformar a realidade da prática pedagógica.

Desta maneira, a formação do Sujeito Professor acontece no momento em que ele assume uma postura dinâmica. As trocas que ocorrem, de maneira processual e contínua na qualificação profissional, fazem parte da movimentação de recursos individuais e sociais que transforma o contexto e ao mesmo tempo o Sujeito Professor.

\begin{tabular}{|l|l|}
\hline Você precisa se aperfeiçoar, você não pode ficar no seu \\
Professora-4 \\
"feijão com arroz", porque no nosso mundo, a globaliza- \\
ção, a cada um minuto, já tem coisas evoluindo. Como é \\
que você vai ficar no seu quadro e giz? Você não pode. Até \\
porque, as crianças evoluem também. As crianças de hoje \\
não são as mesmas de alguns anos atrás. Eu tenho 25 \\
anos, eu já sou bem arcaica. A minha infância, comparada \\
a deles, é muito diferente. Então, como é que um professor \\
vai ser desatualizado? Não pode. O aluno não vai gostar \\
da sua aula, não vai ter interesse para vir estudar. Você \\
tem que se aperfeiçoar para o seu aluno ter vontade de \\
vir à escola, de aprender, e a sua mudança vai ajudar na \\
aprendizagem dele né? Vai interferir. Se você só ficar lá \\
no livro, giz e quadro, ele vai achar aquilo monótono. E se \\
ele for maior, vai evadir da escola. Por isso que precisa se \\
aperfeiçoar, se atualizar. Hoje não existe mais você ter só \\
a graduação.
\end{tabular}

Dessa maneira, diante da imensa subjetividade presente na sua prática, não pode lidar com ela somente aplicando técnicas de sua bagagem de conhecimento profissional. $\mathrm{O}$ conhecimento de novos saberes se desenvolve quando $o$ sujeito assume a postura de reflexão crítica sobre a prática (Freire, 1996).

Diante dessa realidade, quando não se possibilita um ambiente reflexivo, cria-se a corrente da alienação e da resistência às mudanças. É preciso considerar a coordenação pedagógica como espaço onde o Sujeito Professor irá se reunir para avaliar, sugerir e refletir a sua realidade. 
Revista de la Escuela de Ciencias de la Educación, año 14, nRo. 13, vol. 1, enero a junio de 2018. Páginas 19-39. ISSN 1851-6297 (DESDE DICIEMBRE DE 2006 A DICIEMBRE DE 2017). ISSN 2362-3349 (EN LINNEA). COORDENAÇAO PEDAGÓGICA e Seus elementos fundamentais. Sonaly Carvalho de Miranda da Silva.

Ao refletir na ação, as situações problemas são encaradas de maneira inovadora e, ao definir os meios e os fins interativamente, decide o caminho mais relevante para solucionar a situação. Segundo Tardif (2012), "as situações de trabalho colocam na presença uns dos outros seres humanos que devem negociar e compreender juntos o significado de seu trabalho coletivo" (p. 266).

Daí, vemos a importância da reflexão do "eu", isto é, refletir criticamente suas ideologias e suas ações na busca da qualidade da prática profissional para a qual é indispensável uma postura aberta para a mudança.O espaço da coordenação pedagógica possibilita, assim, o ambiente coletivo para o Sujeito Professor se auto avaliar, construir conhecimento pedagógico e reconstruir a sua prática.

\section{4 - Considerações finais}

Este estudo permitiu compreender que existem elementos presentes na coordenação pedagógica da escola, fundamentais para que os sujeitos nela envolvidos adquiram saberes ou aprofundem conhecimentos e, assim, contribuam para a melhor organização do trabalho pedagógico na escola e na sala de aula. Reconhecemos primeiramente o Sujeito Professor como um ser histórico, constituído de subjetividade, que sofre e exerce influência no ambiente social onde se encontra. Devido a que seja um ser histórico, carrega consigo as experiências vividas ao largo de sua vida e que estão constantemente dialogando com seu inter e com seu extra individual. Por tanto, o desenvolvimento subjetivo e profissional do Sujeito Professor compreende a relação dialética e reflexiva, suas emoções e pensamentos, em busca da inteligibilidade sobre a realidade e sobre seu próprio eu. Portanto, ele precisa ser respeitado para se sentir feliz, amparado e motivado, para realizar suas atividades de maneira prazerosa. Caso contrário, seu desprazer irá contaminar a sala de aula e os demais sujeitos envolvidos no processo de ensino aprendizagem.

Verificou-se que o espaço/tempo da coordenação pedagógica propicia ao Sujeito Professor, o processo de idas e voltas, de possibilidades e de movimentos diversos, que constituem a dinâmica de seu desenvolvimento subjetivo e profissional.

Baseada na ideia do desenvolvimento oriundo das interações sociais, a categoria Relações surge onde o coletivo proporciona a intervenção ativa do Sujeito Professor, mediado por outro mais experiente, em um ambiente estruturado pela cultura ali existente. Nossas ponderações e discussões nos remeteram a subjetividade do pertencimento, que ocorre quando existe acolhimento, confiança e envolvimento. A emoção do pertencimento facilita o enfrentamento e a superação dos obstáculos e cria a possibilidade de uma nova postura diante da realidade. Todo este envolvimento gera o compromisso de reflexão e reavaliação, respeitando sempre o processo dinâmico de equipe, na construção da identidade coletiva. Assim, o hábito adquirido na vivência coletiva nos fornece 
Revista de la Escuela de Ciencias de la Educación, año 14, nRo. 13, vol. 1, enero a junio de 2018. Páginas 19-39. ISSN 1851-6297 (DESDE DICIEMBRE DE 2006 A DICIEMBRE DE 2017). ISSN 2362-3349 (EN LINEA). CoORDENAÇAO PEDAGÓGICA e seus elementos fundamentais. Sonaly Carvalho de Miranda da Silva.

subsídios para vencer o medo de se envolver, de dialogar, de interagir, de se aventurar na busca do que é verdadeiro e melhor para o grupo.

Quanto à organização da Escola, percebemos que as ações realizadas na coordenação pedagógica só funcionam se estiverem em parceria com o administrativo da escola e se for efetivamente realizada. Essa ideia implica em comunicação e participação, que juntas constroem redes sociais que busca estabelecer relações democráticas. A organização do trabalho pedagógico, quando adota a dimensão de poder descentralizado, dá a cada sujeito a oportunidade de assumir a liderança em determinado momento de acordo com seus saberes. Julgamos ser importante ao gestor escolar estar aberto e conscienteda necessidade da descentralização do poder, para que todos possam assumir efetivamente e com clareza o seu papel dentro da escola. Consideramos também, que as questões pedagógicas são mais importantes do que as questões administrativas. E se porventura houver disputa entre o administrativo e o pedagógico é a Liderança Pedagógica que deverá sobressair e não a liderança administrativa, apesar de haver a necessidade do administrativo para organizar a estrutura necessária ao funcionamento da escola.

Quanto ao espaço/tempo da coordenação pedagógica, como espaço de Formação, é fundamental admitir que a formação é fenômeno que não acontece por meio de imposição. É importante que exista internamente, algum elemento provocador que induza ao aprendizado. Para isto, deve-se levar em conta que a postura reflexiva e de pesquisa do Sujeito Professor acontece quando ele se posiciona curioso e motivado a solucionar problemas que tenham relação direta com o trabalho realizado no seu cotidiano. Assim, o espaço/tempo da coordenação pedagógicase caracteriza como espaço de formaçãocontinuada, à medida que busca o equilíbrio entre os saberes adquiridos nas universidades e aqueles originários das práticas cotidianas no magistério.

Por fim, cabe destacar que a realização efetiva da coordenação pedagógica na escola não acontece efetivamente, somente por força da lei. Destacamos a necessidade da Liderança Pedagógica ao reconhecer que somente ela cria condições para o sujeito professor participar, se auto avaliar, assumir compromissos, adquirir o sentimento de pertencimento e desenvolver competências coletivas. Na dimensão social é a liderança Pedagógica que propicia o diálogo e cria a rede de relações para compartilhar vivencia e construir a identidade do grupo e o princípio da cooperação. Com a Liderança Pedagógica a escola consegue se organizar sistematicamente ao refletir e planejar metas de maneira dinâmica e coligada, buscando sempre a unidade nas ações ao agregar e articulartodo o processo pedagógico da escola. E para fechar o ciclo, a Liderança Pedagógica promove segurança e equilíbrio na equipe ao propiciar a expressão de diferentes modos de pensar e agir gerando confiança liberdade e sucesso. 
Revista de la Escuela de Ciencias de la Educación, año 14, nRo. 13, vol. 1, enero a junio de 2018. Páginas 19-39. ISSN 1851-6297 (DESDE DICIEMBRE DE 2006 A DICIEMBRE DE 2017). ISSN 2362-3349 (EN LINEA). COORDENAÇAO PEDAGÓGICA e Seus elementos fundamentais. Sonaly Carvalho de Miranda da Silva.

Porém, é inegável, que a Liderança Pedagógica não acontece no simples fato de se assumir função administrativa predeterminada ou por escolhas externas. Ela se expressa de maneira intencional e precisa serassumida no espaço escolar, independentemente de ser o coordenador ou outra pessoa da equipe gestora. O importante é que alguém assuma esse papel.

Sem a pretensão de oferecer respostas prontas a serem aplicadas em quaisquer situações, moveu-nos a intenção de apresentar elementos norteadores na construção de uma coordenação pedagógica que visa contribuirpara que os sujeitos nela envolvidos possam adquirir saberes, numa perspectiva de aprimorar, alterar ou aprofundar o que se pretende alcançar, para melhor organização do trabalho pedagógico na escola e na sala de aula.

\section{Referências:}

- Cunha, M. D. (2005). Subjetividade e constituição de professores. In F. González Rey (Orgs.), Subjetividade, complexidade e pesquisa em psicologia (pp. 191-213). São Paulo: Pioneira Thomson Learning.

- Currículo em Movimento da Educação Básica do Distrito Federal: Pressupostos Teóricos. (2014). Brasília: Secretaria de Estado de Educação do Distrito Federal.

- Creswell, J. W. (2010). Projeto de pesquisa: métodos qualitativos, quantitativos e misto (3a ed.). (M. Lopes, trad.). Porto Alegre: Artmed. (Obra original publicada em 2009).

- Demo, P. (2002). Professor e seu direito de estudar. Em A. S. Neto \& L. S. B. Maciel (Orgs.). Reflexões sobre a formação de professores (pp. 71-88). Campinas, São Paulo: Papirus.

- Freire, P. (1996). Pedagogia da autonomia: saberes necessários à pratica educativa. São Paulo: Paz e Terra, (Coleção Leitura).

- González Rey, F. (1999). La investigación cualitativa en psicología: rumbos y desafíos. São Paulo: EDUC.

- González Rey, F. (2003). El aprendizaje en el enfoque histórico-cultural: sentido y aprendizaje. En: E. F. A. Tabelli \& S. M. Chaves (Org.). Concepções e práticas em formação de professores: diferentes olhares. Rio de janeiro: Alternativa e DP\&A.

- González Rey, F. (2005). Pesquisa qualitativa e subjetividade: os processos de construção da informação. São Paulo: Pioneira Thomson Learning.

- Índice de Desenvolvimento da Educação Básica 2012. (2012). Recuperado em 22 de setembro de 2012, de http://www.portalideb.com.br

- Lakatos, E. M. \& Marconi, M. A.(2003). Fundamentos de metodologia científica (5a ed.). São Paulo: Atlas.

- Lei no 9.394 de 20 de dezembro de 1996. (1996, 23 de dezembro). Estabelece as Diretrizes e Bases da Educação Nacional. Brasil: Diário Oficial da União, seção 1 Consultado em 29 de outubro de 2014 dehttp://www2.camara.leg.br/legin/fed/lei/1996/ lei-9394-20-dezembro-1996-362578-publicacaooriginal-1-pl.html

- Lei $n^{\circ}$ 4.751, de 07 de fevereiro de 2012. (2012, 8 de fevereiro). Dispõe sobre o Sistema de Ensino e a Gestão Democrática do Sistema de Ensino Público do Distrito Federal. 
Revista de la Escuela de Ciencias de la Educación, año 14, nRo. 13, vol. 1, enero a junio de 2018. Páginas 19-39. ISSN 1851-6297 (DESDE DICIEMBRE DE 2006 A DICIEMBRE DE 2017). ISSN 2362-3349 (EN LINEA). COORDENAÇAO PEDAGÓGICA e seus elementos fundamentais. Sonaly Carvalho de Miranda da Silva.

Brasília, DF: Poder Executivo. Consultado em 12 de outubro de 2012 de http://www. sinprodf.org.br/servicos/legislaçao/

- Maturana, R. H. (1997). De maquinas e seres vivos, autopoiese: a organização do vivo. Porto Alegre: Artes Médicas.

- Moran, J. M. (2007). A educação que desejamos: novos desafios e como chegar lá. Campinas, São Paulo: Papirus.

- Nóvoa, A. (1992). Formação de professores e profissão docente. In A. Nóvoa (Org.). Os professores e sua formação. Lisboa: Publicações Dom Quixote.

- Pino, A. (1993). Processos de significação e constituição do sujeito: Temas em Psicologia, 1 (1), 17-24 [online]. ISSN 1413-389X. Consultado em 11 de agosto de 2014, de http://pepsic.bvsalud.org/pdf/tp/v1n1/v1n1a04.pdf

- Pino, A. (1996). Constituição e modos de significação do sujeito no contexto da préescola. [Mimeo]. Em VI Reunião da ANPEPP. Não publicado.

- Projeto Político-Pedagógico professor Carlos Mota. (2012). Secretaria de Estado de Educação. Brasília, DF. Consultado em 27 de outubro de 2014 de https://drive.google. com/file/d/0B90p86NDkzaHbFB6TFpmZV9ZaU0/edit?pli=1

- Projeto Político-Pedagógico da Escola-1 2010/2013. (2010). Projeto realizado na escola. [Mimeo]. Sem numeração de páginas. Não publicado.

- Projeto Político-Pedagógico da Escola-2. (2012). Projeto realizado na escola. [Mimeo]. Sem numeração de páginas. Não publicado.

- Raposo, M. B. T. (2006). A psicologia e a formação de professores: ação e reflexão a partir da percepção de professores em formação. Interação (Vol. 10, pp. 287-300).

- Santos, L. L. C. P. (2002). Formação de professores e saberes docentes. In: A. S. Neto \& L. S. B. Maciel (Orgs.). Reflexões sobre a formação de professores. (pp. 89-113). Campinas, São Paulo: Papirus.

- Santos, E. B. (2013). O professor em situação social de aprendizagem: autoctonia e formação docente. Tese de Doutorado em Educação, Universidade de Brasília, Brasília, DF.

- Schön, D. A. (2000). Educando o profissional reflexivo: um novo design para o ensino e a aprendizagem. Porto Alegre: Artes Médicas Sul.

- Tardif, M. (2012). Saberes docentes e formação profissional. Petrópolis, RJ. Vozes.

- Vasconcellos, C. dos S. (2008). Coordenação do Trabalho Pedagógico: Do projeto político-pedagógico ao cotidiano da sala de aula. São Paulo: Libertad.

- Veiga, I. P. A. (2001). As dimensões do Projeto Político-Pedagógico: Novos desafios para a escola. (Orgs.). Campinas, SP: Papirus (Coleção Magistério: Formação e Trabalho Pedagógico)

- Weber, L. N. D. (2011). Pensando a família: instrumentos para coleta e análise de dados. Curitiba: Juruá. 